\title{
NOTES AND CORRESPONDENCE Modulation of the Diurnal Cycle of Precipitation near the Southwestern Coast of Sumatra by Mixed Rossby-Gravity Waves
}

\author{
Biao GENG, Masaki KATSUMATA, and Kyoko TANIGUCHI \\ Global Ocean Observation Research Center, JAMSTEC, Yokosuka, Japan
}

(Manuscript received 10 March 2019, in final form 10 January 2020)

\begin{abstract}
In this study, we investigated the impact of mixed Rossby-gravity waves (MRGWs) on the diurnal cycle of precipitation over the southwestern coastal area of Sumatra using data captured during a pilot field campaign of the Years of the Maritime Continent (YMC) project. The study focused on a 19-day period from 24 November to 12 December 2015, using data from intensive surface observations, radiosondes, and a C-band polarimetric radar (collected aboard the research vessel Mirai at $4^{\circ} 4^{\prime} \mathrm{S}, 101^{\circ} 54^{\prime} \mathrm{E}$ ), as well as data from a global objective analysis. The results indicated a relationship between oscillations with periods of several days in the intensity of diurnal precipitation and the wind field. Wind oscillations were attributed to several westward-propagating MRGWs traversing the study site. Diurnal convection and precipitation over the land and ocean were enhanced (suppressed) when MRGW-induced offshore (onshore) wind perturbations dominated. Large-scale low-level convergence and upper-level divergence, stronger sea-breeze flow, and colder land-breeze flow were also observed with the intensification of MRGW-induced offshore wind perturbations. However, diurnal precipitation displayed a similar well-defined phase and propagation pattern over the land and ocean, coherent with the regular evolution of seaand land-breeze circulations, regardless of wind perturbations induced by MRGWs. The results suggest that local convergence induced by the land-sea contrast is mainly responsible for driving the diurnal cycle. Notwithstanding, MRGWs exert a significant impact on the amplitude of diurnal convection and precipitation by modulating the large-scale dynamic structure of the atmosphere and the intensity of local sea- and land-breeze circulations.
\end{abstract}

Keywords mixed Rossby-gravity waves; Sumatra; diurnal cycle of precipitation

Citation Geng, B., M. Katsumata, and K. Taniguchi, 2020: Modulation of the diurnal cycle of precipitation near the southwestern coast of Sumatra by mixed Rossby-gravity waves. J. Meteor. Soc. Japan, 98, 463-480, doi:10.2151/ jmsj.2020-026.

\section{Introduction}

There are widespread diurnal variations of precipitation over the Maritime Continent, attributed to diurnally forced sea and land breezes (Yang and Slingo 2001; Hadi et al. 2002; Yamanaka 2016). Diurnal con-

Corresponding author: Biao Geng, Global Ocean Observation Research Center, Japan Agency for Marine-Earth Science and Technology, 2-15 Natsushima, Yokosuka, 237-0061, Japan E-mail: bgeng@jamstec.go.jp

J-stage Advance Published Date: 6 February 2020 vective activity in this region generates a large amount of heat and is, therefore, a great source of energy for atmospheric circulation (Ramage 1968).

Among the islands of Indonesia, diurnal convection over the western and southwestern coastal areas of Sumatra is extremely active and has received a considerable amount of attention. As illustrated by previous observational studies (e.g., Renggono 2001; Mori et al. 2004; Kawashima et al. 2006; Sakurai et al. 2011; Yokoi et al. 2017), diurnal cycles of precipitation around the western and southwestern coastal areas of 
Sumatra share common features. Associated with the development of local sea and land breezes, diurnal precipitation in these regions usually propagates inland and peaks in the afternoon, followed by migration offshore and the reinforcement of precipitation over the nearby ocean at night. New convection can be generated successively over the sea-breeze front during the afternoon and over the land-breeze front overnight.

The amount of rainfall over the ocean west of Sumatra during nighttime can be much larger as compared with that of afternoon rainfall over land (Mori et al. 2004). It is thought that diurnal convection over land during the afternoon hours plays an important role in enhancing nighttime convection and rainfall over the ocean. Several physical mechanisms for this enhancement have been proposed, including the seeder-feeder process over the ocean induced by the anvil clouds of land convection (Mori et al. 2004), the enhancement of the land breeze as a result of afternoon convection over land (Wu et al. 2009; Sakurai et al. 2011), and the intensification of updrafts over the ocean caused by gravity waves emanating from land convection (Mori et al. 2004; Yokoi et al. 2017). Sakurai et al. (2011) also found that a larger precipitation system formed over the ocean following the merger of the precipitation system migrating from the land with newly generated ocean convection.

Large-scale atmospheric disturbances propagating over Sumatra exert an influence on the phase, amplitude, migration, and morphology of local diurnal precipitation. Many studies have detailed the modulation of the diurnal cycle of precipitation around Sumatra associated with convectively inactive and active phases of intraseasonal oscillation or the MaddenJulian Oscillation (Madden and Julian 1972), which traverse the region episodically over dozens of days (e.g., Kawashima et al. 2006; Ichikawa and Yasunari 2007; Hamada et al. 2008; Fujita et al. 2011; Mori et al. 2011; Rauniyar and Walsh 2011; Kamimera et al. 2012; Peatman et al. 2014; Vincent and Lane 2017). However, to date, few studies have investigated the variability of local diurnal precipitation associated with higher-frequency tropical waves that traverse Sumatra over several days.

Baranowski et al. (2016) found that if convectively coupled Kelvin waves arrive in phase with the diurnal cycle over Sumatra, then diurnal precipitation will be enhanced by a factor of $>5$. Mixed Rossby-gravity waves (MRGWs) are another high-frequency tropical wave traversing Sumatra (Widiyatmi et al. 2001; Takasuka et al. 2019). Although Kawashima et al.
(2011) emphasized the role of a westward-propagating MRGW in the formation of damaging surface winds under a mesoscale convective system in western Sumatra, little is known about the modulation of diurnal precipitation around Sumatra as a result of MRGWs.

During a pilot field campaign of the Years of the Maritime Continent (YMC) project (Yokoi et al. 2017), intensive observations using the research vessel Mirai were conducted in the Indian Ocean, approximately $50 \mathrm{~km}$ off the southwestern coast of Sumatra, from late November to mid-December 2015. During the early and middle stages of the observation period, precipitation demonstrated a pronounced diurnal cycle over both the land and the ocean (Yokoi et al. 2017). As shown in Section 3 of this study, several MRGWs traversed the region and induced episodic and distinct large-scale background circulations over Sumatra during this period. The aim of this study is to investigate the variability of the diurnal cycles of precipitation and local environment associated with MRGWs around the southwestern coast of Sumatra.

\section{Data and methods}

Surface observations, radiosonde flights, and measurements using a C-band polarimetric radar aboard the research vessel Mirai were conducted in the Indian Ocean at $4^{\circ} 4^{\prime} \mathrm{S}, 101^{\circ} 54^{\prime} \mathrm{E}$ (Fig. 1). The Mirai polarimetric radar has been operated since the summer of 2014 (Katsumata 2014). Table 1 shows the major operating characteristics of the Mirai polarimetric radar.

We herein analyzed data from 0000 UTC 24 November to 0000 UTC 13 December 2015, when diurnal convection was pronounced over the observation site (Yokoi et al. 2017). Radiosonde observations were conducted on a three-hourly basis, and the shipborne polarimetric radar performed volume scans every 6 min in elevation angles from $0.5^{\circ}$ to $40^{\circ}$ (or $33.5^{\circ}$ ). The radar range of volume scans was $100 \mathrm{~km}$ (Fig. 1). The attenuation of reflectivity was corrected using the linear differential phase method (Bringi et al. 1990), with an attenuation correction coefficient of 0.072 being obtained experimentally by applying the method of Carey et al. (2000) to the observed data.

The volume-scan data of the radar were interpolated onto Cartesian grids using a Cressman (1959) weighting scheme, with horizontal and vertical grid intervals of 1 and $0.5 \mathrm{~km}$, respectively. Reflectivity data at an altitude of $2 \mathrm{~km}$ were used for convective-stratiform partitioning (Yuter and Houze 1998) and rainfall estimation through the reflectivity-rainfall rate relationship suggested by Keenan et al. (2000). As it is 


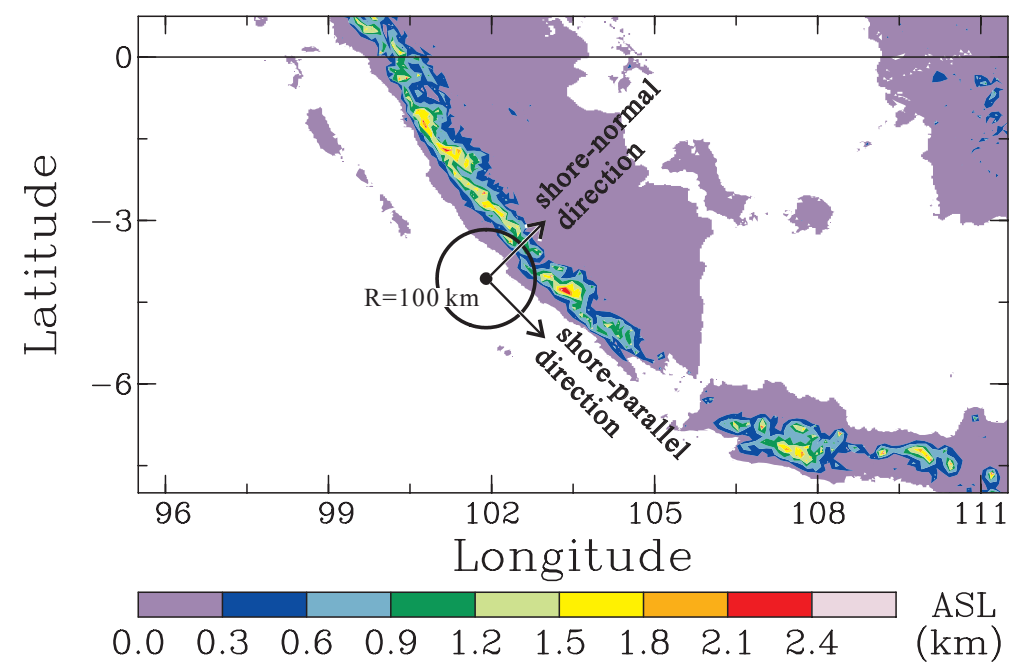

Fig. 1. Topographical map of the study site. The circle radius is $100 \mathrm{~km}$ from the research vessel Mirai, showing the range of the radar data. The arrows indicate shore-normal and shore-parallel directions as labeled.

not possible to validate rainfall estimations over the ocean, radar-derived rainfall was analyzed only in a relative sense. Frequency-altitude diagrams (FADs) of reflectivity with an interval of $1 \mathrm{dBZ}$ were constructed following Yuter and Houze (1995). Similar to Mandapaka et al. (2013), each FAD was normalized using the total number of occurrences.

Large-scale conditions during the study period were ascertained from grid point values of global objective analysis data (hereafter called GPV data) from the Japan Meteorological Agency (Nakagawa 2009). To isolate large-scale disturbances associated with MRGWs, a Lanczos bandpass filter of 211 weights (Duchon 1979) was applied both in time and in zonal space. Based on previous studies (e.g., Wheeler and Kiladis 1999; Roundy and Schreck 2009), the filter included periods of 3.5-5.5 days and wavenumbers of $1-20$.

\section{Variations of precipitation and large-scale circulation during the study period}

Figure $2 \mathrm{a}$ shows a time series of radar-derived volume rainfall, which is defined as the integral of the multiplication of the rainfall rate at each pixel by the pixel area and is commonly used to assess the temporal variability of local precipitation (e.g., Lang et al. 2007; Jackson et al. 2009). Figure 2a indicates a pronounced diurnal cycle and peak diurnal rainfall characterized by multiday variations. To characterize the variability of this diurnal cycle, a volume rainfall threshold was used to designate precipitation as
Table 1. Major operating characteristics of the polarimetric radar aboard the research vessel Mirai.

\begin{tabular}{ll}
\hline \multicolumn{1}{c}{ Item } & \multicolumn{1}{c}{ Description } \\
\hline Frequency & $5370 \mathrm{MHZ}$ \\
Antenna diameter & $4 \mathrm{~m}$ \\
Antenna gain & $45 \mathrm{~dB}$ \\
3-dB beamwidth & $1.0^{\circ}$ \\
Transmitter type & Solid-state \\
Pulse configuration & Using pulse-compression \\
Polarization & Simultaneous H and V \\
Peak power & $6 \mathrm{~kW}$ per polarization \\
Receiver dynamic & $110 \mathrm{~dB}$ \\
range & \\
Minimum detect- & $-111 \mathrm{dBm}$ \\
able signal & \\
Pulse width & $1 \mu \mathrm{s}$ (range $<12 \mathrm{~km})$ and \\
& $64 \mu \mathrm{s} \mathrm{(range} \geq 12 \mathrm{~km})$ \\
& for Elv. $\leq 0.5^{\circ}$
\end{tabular}



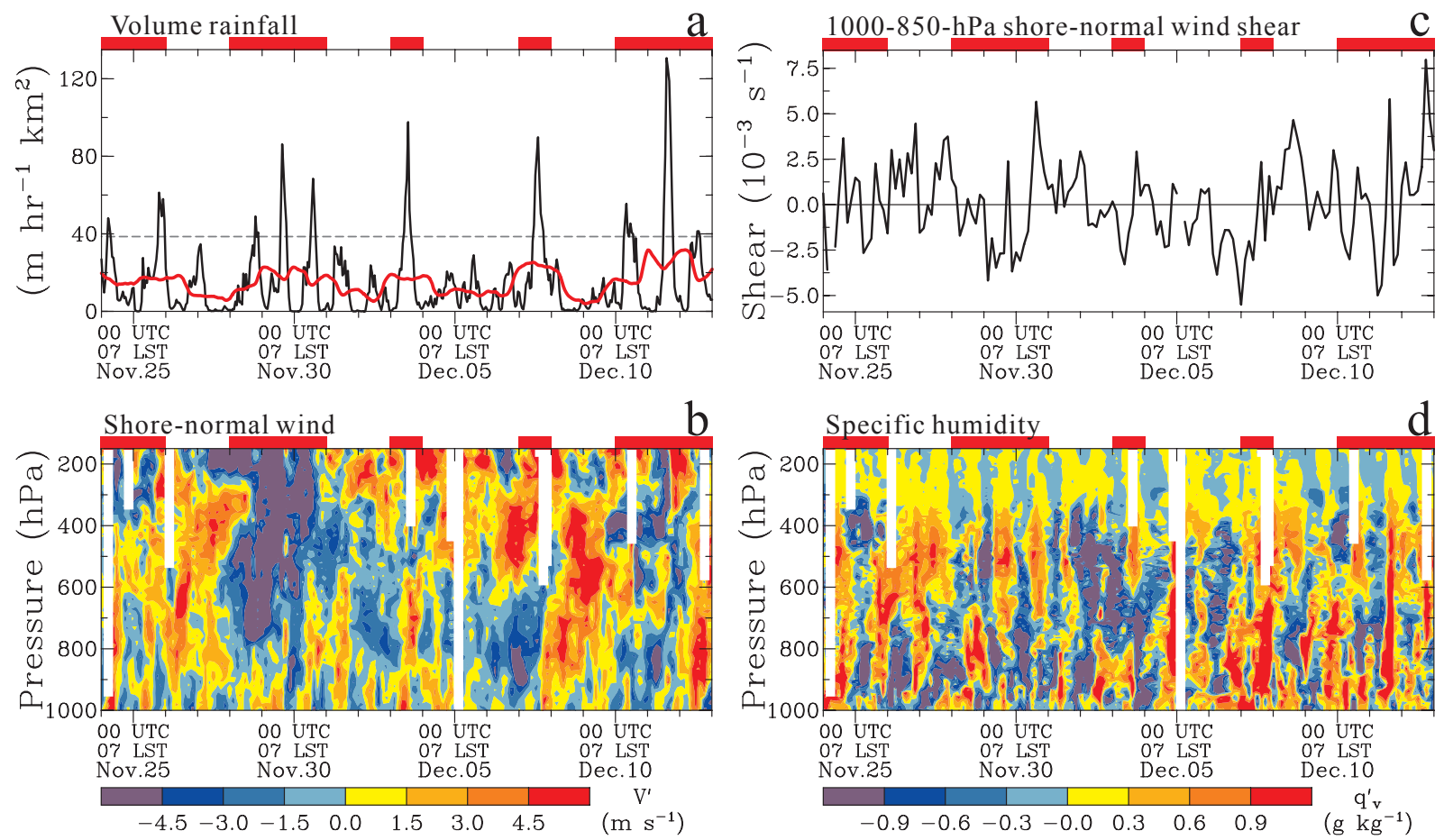

Fig. 2. (a) Time series of volume rainfall (black curve, $\mathrm{m} \mathrm{h}^{-1} \mathrm{~km}^{2}$ ) estimated from radar data. The red curve indicates the 1.5-day running mean. The horizontal dashed line indicates a volume rainfall of $38.6 \mathrm{~m} \mathrm{~h}^{-1} \mathrm{~km}^{2}$. (b) Time-height section of the anomalous shore-normal wind component (color shades, $\mathrm{m} \mathrm{s}^{-1}$ ) observed by radiosonde. The white areas denote missing data due to the loss of the radiosonde signal. (c) Time series of the anomalous shore-normal 1000-850 hPa wind shear (curve, $10^{-3} \mathrm{~s}^{-1}$ ) observed by radiosonde. (d) Same as (b) but for anomalous specific humidity (color shades, $\mathrm{g} \mathrm{kg}^{-1}$ ). An anomaly is defined as a deviation from the mean value of the study period. In (b) and (c), positive (negative) values represent the component toward land (sea). The horizontal red bars at the top of each panel indicate days with a maximum volume rainfall of $>38.6 \mathrm{~m} \mathrm{~h}^{-1} \mathrm{~km}^{2}$.

having a strong or weak diurnal cycle. The value of the threshold was set to $38.6 \mathrm{~m} \mathrm{~h}^{-1} \mathrm{~km}^{2}$, which was twice as high as the standard deviation of volume rainfall. Based on this designation, there were 10 (9) days with a strong (weak) diurnal cycle.

The low-level shore-normal wind component observed by radiosonde exhibited a pronounced diurnal variation (Fig. 2b). A relationship existed between the intensification of offshore winds (negative values) from the lower to the upper troposphere and the occurrence of strong diurnal precipitation. Low-level offshore wind shear (negative values) was enhanced on days with a strong diurnal cycle (Fig. 2c). Specific humidity derived from radiosonde data also exhibited a pronounced diurnal variation (Fig. 2d). From 1 to 7 December, relatively dry air, as evidenced by a decrease in specific humidity, was observed in the $800-400 \mathrm{hPa}$ layer. However, the decrease in humidity was not as drastic as the dry-air intrusion induced by MRGWs (e.g., Numaguti et al. 1995; Yasunaga et al. 2010).

Figure 3 shows the bandpass-filtered $700 \mathrm{hPa}$ wind field from the GPV data. During strong diurnal cycles, northeasterly (offshore) wind perturbations dominated over the radar domain (Fig. 3a). Conversely, southwesterly (onshore) wind perturbations prevailed during weak diurnal cycles (Fig. 3b). Northeasterly and southwesterly winds around the study site blew from and into the equatorial region, respectively, where they were sandwiched between two counterrotating gyres. These circulation patterns match the structures of MRGWs (Wheeler and Kiladis 1999; Kiladis et al. 2009). Consequently, wind fluctuations around the study site can be attributed to the passage of MRGWs. MRGW-induced meridional wind oscillations over Sumatra propagated from the region east of $110^{\circ} \mathrm{E}$ (Fig. 3c); most came from the Pacific Ocean, consistent with the findings of Widiyatmi et al. (2001). 

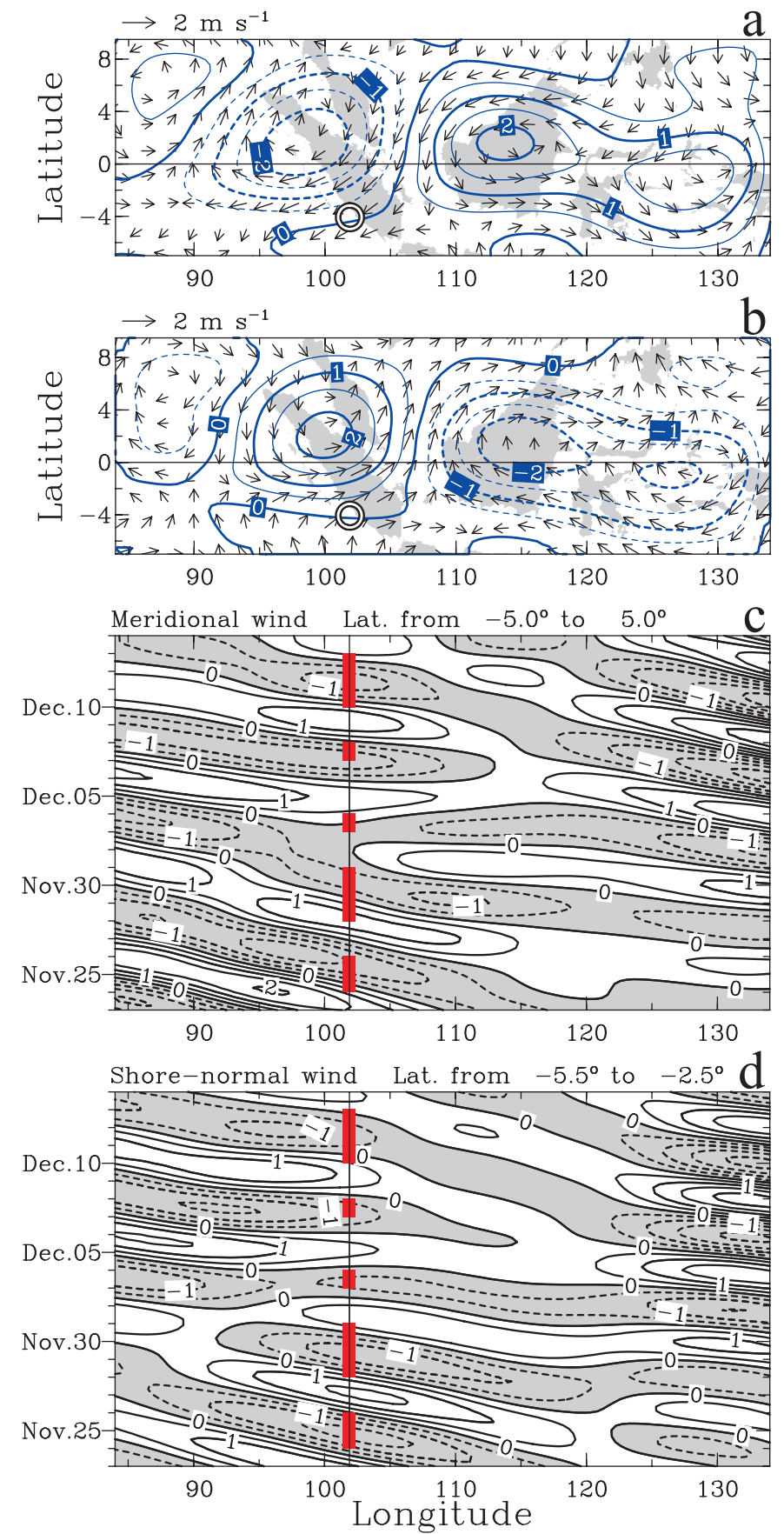

Fig. 3. (a) Mean $700 \mathrm{hPa}$ stream function (blue contours, $10^{5} \mathrm{~m}^{2} \mathrm{~s}^{-1}$ ) and wind (vectors, $\mathrm{m} \mathrm{s}^{-1}$ ) derived from the bandpass-filtered global objective analysis (GPV) data during days with a maximum volume rainfall of $>38.6$ $\mathrm{m} \mathrm{h}^{-1} \mathrm{~km}^{2}$. The circle indicates the radar domain, and land areas are shaded in gray. (b) Same as (a) but for days with a maximum volume rainfall of $\leq 38.6 \mathrm{~m} \mathrm{~h}^{-1} \mathrm{~km}^{2}$. (c) Time-longitude diagram of the $700 \mathrm{hPa}$ meridional wind component (contours, $\mathrm{m} \mathrm{s}^{-1}$ ) derived from the bandpass-filtered GPV data. Negative values (northerly wind perturbations) are shaded in gray. Wind data are averaged from $5^{\circ} \mathrm{S}$ to $5^{\circ} \mathrm{N}$. The location of the research vessel Mirai is indicated by a black vertical line. The vertical red bars illustrate days with a maximum volume rainfall of $>38.6$ $\mathrm{m} \mathrm{h}^{-1} \mathrm{~km}^{2}$. (d) Same as (c) but for the shore-normal wind component (contours, $\mathrm{m} \mathrm{s}^{-1}$ ) averaged from $5.5^{\circ} \mathrm{S}$ to $2.5^{\circ} \mathrm{S}$. Negative values (offshore wind perturbations) are shaded in gray. 

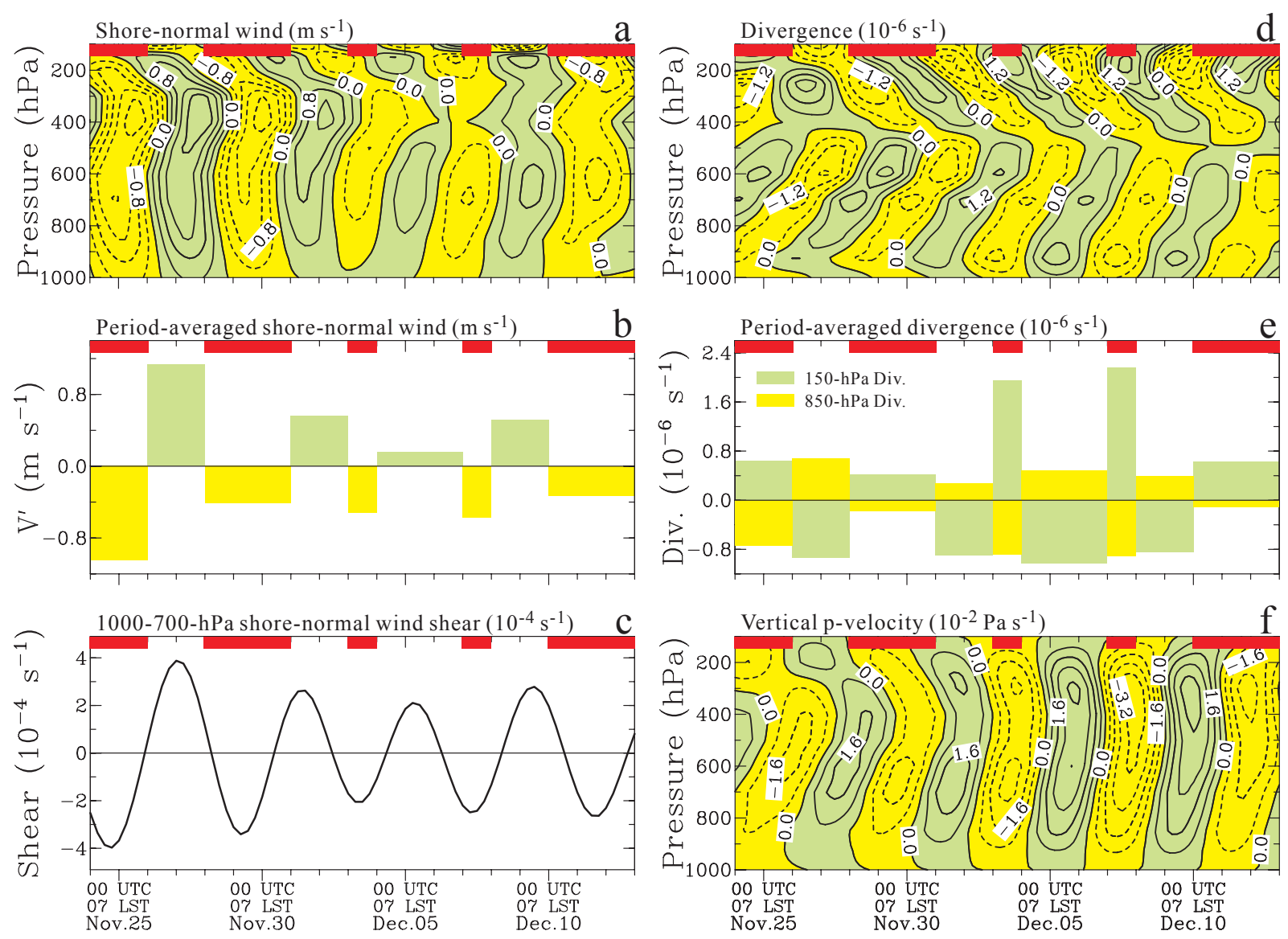

Fig. 4. (a) Time-height section of the shore-normal wind component (contours, $\mathrm{m} \mathrm{s}^{-1}$ ) derived from the bandpassfiltered global objective analysis (GPV) data. Offshore and onshore wind perturbations are shaded in yellow and green, respectively. Wind data are averaged around the study site, from $100^{\circ} \mathrm{E}$ to $103^{\circ} \mathrm{E}$ and from $5.5^{\circ} \mathrm{S}$ to $2.5^{\circ} \mathrm{S}$. (b) Time series of the period-averaged $700-500 \mathrm{hPa}$ shore-normal wind component (yellow bars for offshore winds and green bars for onshore winds, $\mathrm{m} \mathrm{s}^{-1}$ ) derived from the data shown in (a). (c) Time series of the shore-normal 1000-700 hPa wind shear (curve, $10^{-4} \mathrm{~s}^{-1}$ ) derived from the data shown in (a). (d) Same as (a) but for horizontal divergence (contours, $10^{-6} \mathrm{~s}^{-1}$ ). Convergence and divergence perturbations are shaded in yellow and green, respectively. (e) Time series of period-averaged divergence $\left(10^{-6} \mathrm{~s}^{-1}\right)$ at $850 \mathrm{hPa}$ (yellow bars) and $150 \mathrm{hPa}$ (green bars) derived from the data shown in (d). (f) Same as (a) but for vertical p-velocity (contours, $10^{-2} \mathrm{~Pa} \mathrm{~s}^{-1}$ ). Upward and downward motion perturbations are shaded in yellow and green, respectively. The horizontal red bars at the top of each panel indicate days with a maximum volume rainfall of $>38.6 \mathrm{~m} \mathrm{~h}^{-1} \mathrm{~km}^{2}$.

Strong (weak) diurnal cycles occurred with the intensification of MRGW-induced offshore (onshore) wind perturbations (Fig. 3d). The coincidence of strong (weak) diurnal cycles and intensification of offshore (onshore) wind perturbations is also evident in Fig. 4a. These results are consistent with sounding data (Fig. 2b), which showed the intensification of offshore winds during strong diurnal cycles. In particular, period-averaged wind perturbations in the middle troposphere were offshore (onshore) in each period of strong (weak) diurnal cycles (Fig. 4b).
Shore-normal wind perturbations tilted with time (or eastward) in the 700-400 $\mathrm{hPa}$ layer and then tilted westward in the upper troposphere (Fig. 4a). Such vertical tilt of wind perturbations is consistent with the vertical structure of MRGWs observed in other regions (Takayabu and Nitta 1993; Kiladis et al. 2009). During strong diurnal cycles, MRGW-induced offshore 1000-700 hPa wind shear (negative values) was enhanced (Fig. 4c), consistent with the enhancement of low-level offshore wind shear shown by sounding data (Fig. 2c). 

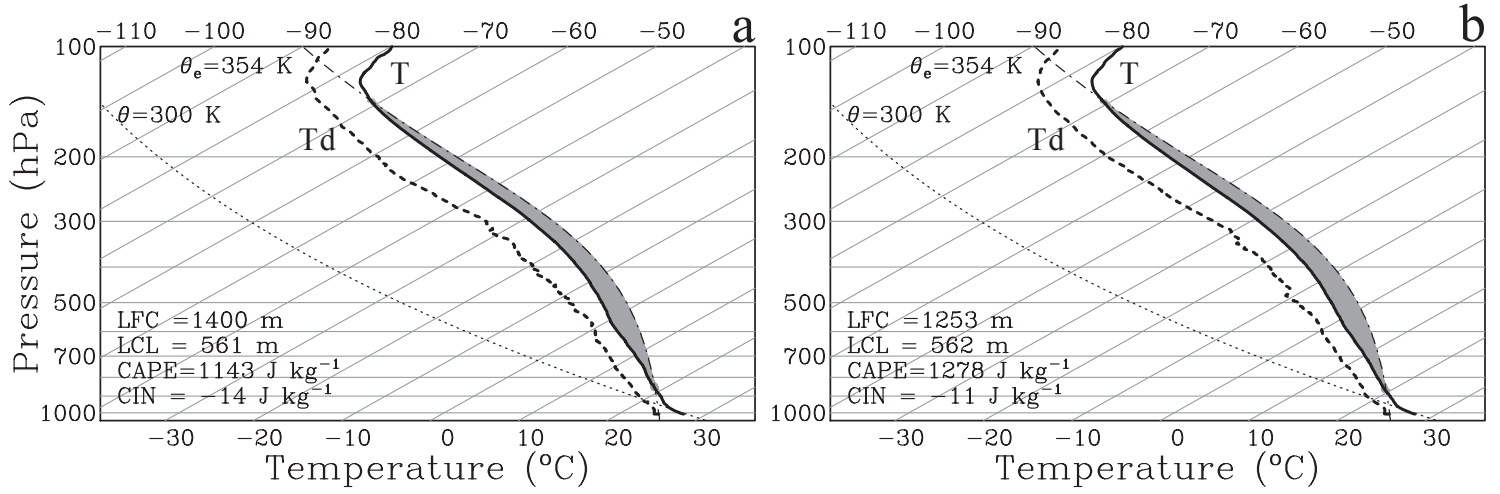

Fig. 5. (a) Skew-T log-P diagram of mean temperature (bold solid curve, ${ }^{\circ} \mathrm{C}$ ) and dew-point temperature (bold dashed curve, ${ }^{\circ} \mathrm{C}$ ) observed by radiosonde during days with a maximum volume rainfall of $>38.6 \mathrm{~m} \mathrm{~h}^{-1} \mathrm{~km}^{2}$. The gray-shaded region indicates the positive area of convective available potential energy (CAPE) based on lifting a pseudoadiabatic parcel from a mixed layer. (b) Same as (a) but during days with a maximum volume rainfall of $\leq 38.6 \mathrm{~m} \mathrm{~h}^{-1} \mathrm{~km}^{2}$.

Around the study site, low-level convergence and divergence were enhanced with the intensification of offshore and onshore wind perturbations, respectively (Figs. 4a, d), consistent with low-level off-equatorial convergence in the off-equatorial flow and divergence in the equatorward flow induced by MRGWs (Kiladis et al. 2009). Upper-level divergence and convergence were also enhanced with the intensification of offshore and onshore wind perturbations, respectively. Strong diurnal cycles were highly correlated with the appearance of MRGW-induced low-level convergence and upper-level divergence (Fig. 4d). Conversely, weak diurnal cycles occurred with the formation of MRGW-induced low-level divergence and upper-level convergence. These features were more apparent in the period-averaged divergence field (Fig. 4e). Updrafts and downdrafts developed in association with offshore and onshore wind perturbations, respectively (Figs. 4a, f). Notably, strong (weak) diurnal cycles occurred with the development of deep updrafts (downdrafts).

The mean thermodynamic profiles (Figs. 5a, b) indicated that the stratification of the atmosphere was similar on days with either strong or weak diurnal precipitation cycles. In both cases, the atmosphere was relatively moist and conditionally unstable, featuring moderate values of convective available potential energy (CAPE) and small values of convective inhibition (CIN).

The above results suggest that the radar-derived strong and weak diurnal cycles are mainly driven by offshore and onshore wind oscillations, respectively, induced by the propagation of MRGWs. Hereafter, offshore and onshore wind regimes induced by MRGWs are referred to as MRGW-offshore and MRGW-onshore wind regimes, respectively. In the following two sections, diurnal precipitation cycles and the local environment are compared between the radar-derived strong and weak diurnal cycles, in other words, between the MRGW-offshore and MRGW-onshore wind regimes, respectively.

\section{Mean diurnal cycle of radar echoes under different regimes}

\subsection{Horizontal distribution of occurrence frequency}

Figure 6 shows the evolution of the horizontal distribution of hourly occurrence frequency, which was calculated on the basis of the number of reflectivity measurements exceeding $10 \mathrm{dBZ}$ divided by the total number of observations within an hour. In both the MRGW-offshore and the MRGW-onshore wind regimes, areas of higher occurrence frequencies of convective and stratiform echoes emerged over land in the afternoon. The areas of higher occurrence frequencies of radar echoes moved away from the coast in the early evening $(\sim 1900 \mathrm{LST}, \mathrm{LST}=\mathrm{UTC}+7)$, developed over the offshore regions before midnight $(\sim 2200$ LST), and then diminished after midnight. These behaviors of the occurrence frequency suggest that, in general, the timing and location of the formation, development, and decay of diurnal precipitation in both regimes are similar.

During the MRGW-offshore wind regime, the magnitude and areal coverage of the occurrence frequency of convective and stratiform echoes after 1600 
MRGW-offshore wind regime
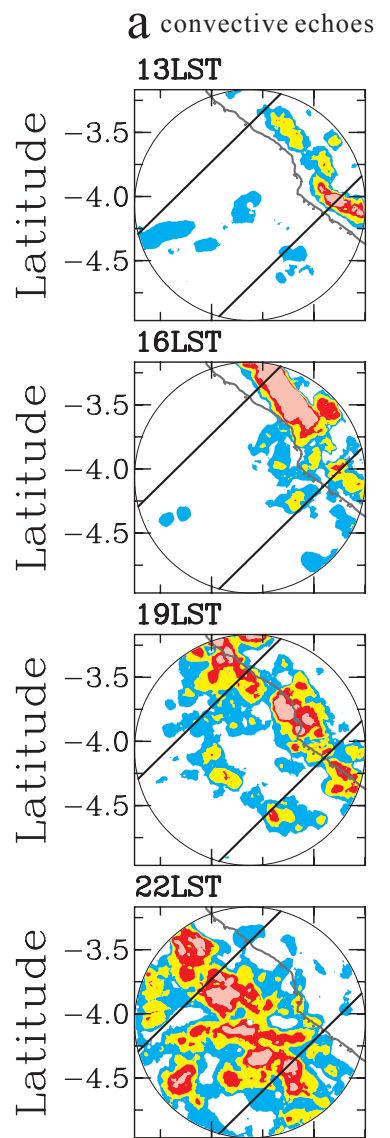

01LST

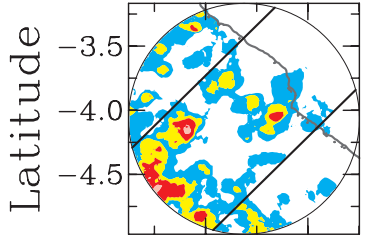

04LST

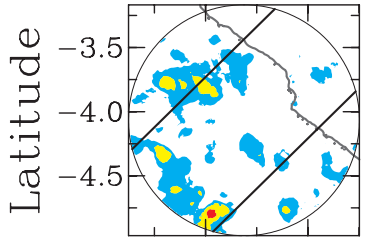

$101.6 \quad 102.4$

Longitude

\begin{tabular}{l|l}
\hline & Freq
\end{tabular} b stratiform echoes

13LST

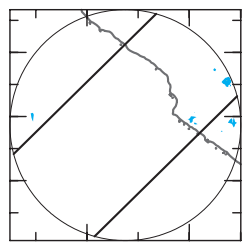

16LST

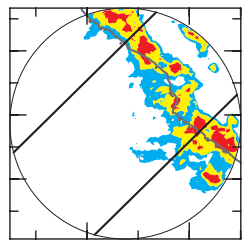

19LST

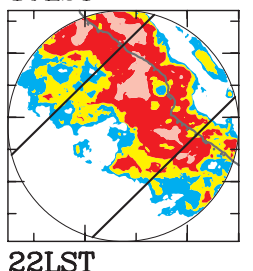

22LST

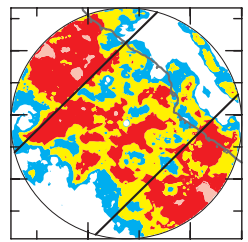

01LST

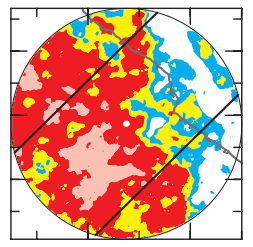

04LST

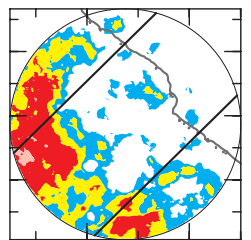

$101.6 \quad 102.4$

Longitude

25354565

(\%)
MRGW-onshore wind regime

C convective echoes

13LST

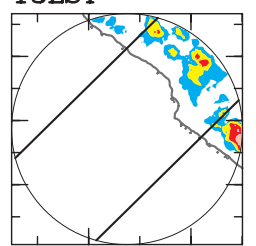

16LST

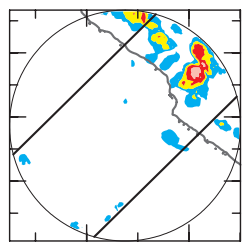

19LST

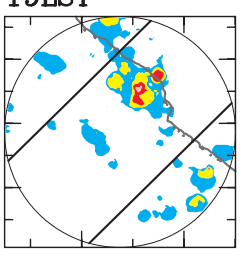

22LST

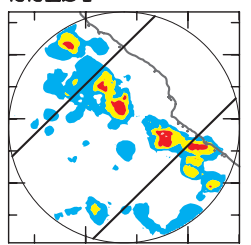

01LST

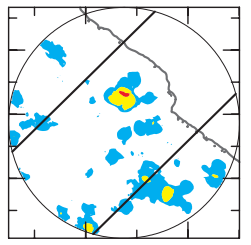

04LST

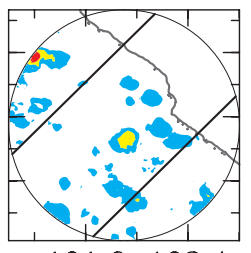

$101.6 \quad 102.4$

Longitude

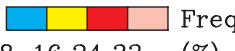

(\%) d stratiform echoes

13LST

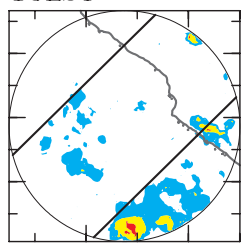

16LST

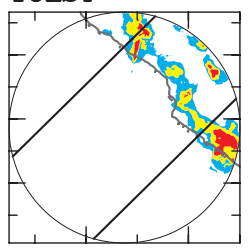

19LST

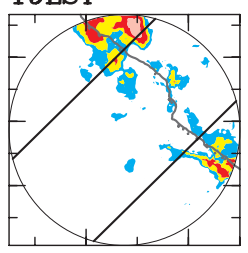

22LST

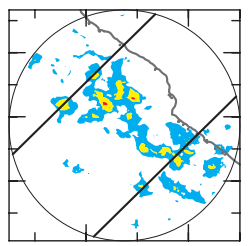

01LST

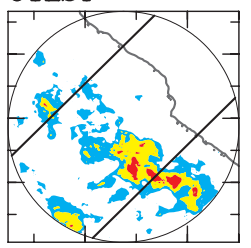

04LST

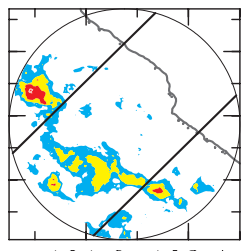

$101.6 \quad 102.4$

Longitude

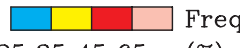

Fig. 6. (a, b) Evolution of hourly occurrence frequency (color shades, \%) centered at the time labeled in each panel with reflectivity values of $\geq 10 \mathrm{dBZ}$ at an altitude of $2 \mathrm{~km}$ for (a) convective echoes and (b) stratiform echoes during the MRGW-offshore wind regime. The region between the two straight lines is used to determine the mean shore-normal vertical sections shown in Figs. 7 and 8, and the coastline is indicated by a gray curve. (c, d) Same as $(\mathrm{a}, \mathrm{b})$ but during the MRGW-onshore wind regime. 
LST were consistently larger as compared with the MRGW-onshore wind regime. This difference suggests that the MRGW-offshore wind regime facilitates more active convection and widespread precipitation.

\subsection{Vertical distribution of occurrence frequency}

Vertical sections of the occurrence frequency of convective echoes are shown in Fig. 7. In both regimes, regions of higher occurrence frequencies featured landward advection in the afternoon and seaward advection from the early evening $(\sim 1700$ LST). These features of the occurrence frequency imply that, on average, diurnal convection in both regimes propagates inland in the afternoon and propagates offshore during nighttime, similar to the findings of Mori et al. (2004). As evidenced by the emergence of new and independent regions with higher occurrence frequencies, the preferential locations for new convection were also similar in both regimes. New convection was triggered on the inland side of the already existing convection during the early afternoon (1300-1500 LST). From the late afternoon $(\sim 1600$ LST), new convection formed on both the offshore and the inland sides of the already existing convection. Similar to the findings of Sakurai et al. (2011), in both regimes, a merger of the convection migrating from the land with newly generated convection offshore was apparent overnight.

The vertical extent of convective echoes differed between the two regimes (Fig. 7). Occurrence frequencies of $\geq 12 \%$ extended beyond an altitude of 14 $\mathrm{km}$ at 1500-1600 LST during the MRGW-offshore wind regime (Fig. 7a); however, they did not reach $12.5 \mathrm{~km}$ during the MRGW-onshore wind regime (Fig. $7 b)$. Furthermore, occurrence frequencies of $\geq 24 \%$ could reach as high as $10 \mathrm{~km}$ over both the land and the ocean during the MRGW-offshore wind regime, while the maximum occurrence frequency was less than $24 \%$ during the MRGW-onshore wind regime. These results imply the development of deeper diurnal convection during the MRGW-offshore wind regime as compared with the MRGW-onshore wind regime.

Figure 8 shows the vertical distribution of the hourly occurrence frequency of a specific differential phase $\left(K_{\mathrm{DP}}\right)$ exceeding $0.3^{\circ} \mathrm{km}^{-1}$ in stratiform echoes. This threshold of $K_{\mathrm{DP}}$ is above the typical measurement error of $K_{\mathrm{DP}}$ at the C-band $\left(\sim 0.2^{\circ} \mathrm{km}^{-1}\right.$; e.g., Bechini et al. 2013). The calculation of the occurrence frequency of $K_{\mathrm{DP}}$ is similar to that of the reflectivity shown in Section 4.1. For both regimes, stratiform precipitation was characterized by a region of high frequency centered near an altitude of $10 \mathrm{~km}$, where the temperature was approximately $-30^{\circ} \mathrm{C}$. This result implies the enhancement of $K_{\mathrm{DP}}$ values in the ice region of stratiform precipitation.

As indicated by previous studies (e.g., Bechini et al. 2013), the elevated region of enhanced $K_{\mathrm{DP}}$ in stratiform precipitation is related to an increase in the concentration and/or the growth of ice hydrometeors. Comparing Fig. 8 with Fig. 7 revealed that the enhancement of $K_{\mathrm{DP}}$ aloft in stratiform precipitation was associated with the development of convective precipitation, indicating that the enhancement of snow and ice particles aloft by deep convection (e.g., Houze 1989) plays an important role in the development of stratiform precipitation in both regimes.

The magnitudes and vertical and horizontal extensions of the frequency of higher $K_{\mathrm{DP}}$ values aloft in stratiform precipitation were much larger during the MRGW-offshore wind regime as compared with the MRGW-onshore wind regime (Fig. 8). These differences were most prominent at night over the ocean, where diurnal convection occurred over a much larger area under the MRGW-offshore wind regime (Fig. 7a). These results suggest that, under the MRGW-offshore wind regime, stratiform clouds involve more robust ice hydrometeors.

\subsection{FAD}

Convective FADs during the MRGW-offshore and MRGW-onshore wind regimes are shown in Figs. 9a and $9 \mathrm{~b}$, respectively. Before 1600 LST, when diurnal convection mainly occurred over land (Fig. 6), convective FADs in both regimes exhibited a relatively high occurrence of reflectivity values of $>40 \mathrm{dBZ}$. Over the land, the mean convective reflectivity values near the surface during the MRGW-offshore wind regime were slightly larger as compared with those during the MRGW-onshore wind regime. From 1900 to 0400 LST, when diurnal convection occurred mainly over the ocean (Fig. 6), convective FADs indicated that the occurrence of reflectivity values of $>40 \mathrm{dBZ}$ in the MRGW-offshore wind regime was larger as compared with those in the MRGW-onshore wind regime. Over the ocean, the mean convective reflectivity values near the surface under the MRGW-offshore wind regime were approximately $2 \mathrm{dBZ}$ larger than those of the MRGW-onshore wind regime. These results indicate that diurnal convection, especially that which evolves over the ocean, is stronger under the MRGW-offshore wind regime than under the MRGW-onshore wind regime.

Figures $9 \mathrm{c}$ and $9 \mathrm{~d}$ show that the occurrence of relatively high reflectivity was enhanced above the 
MRGW-offshore wind regime

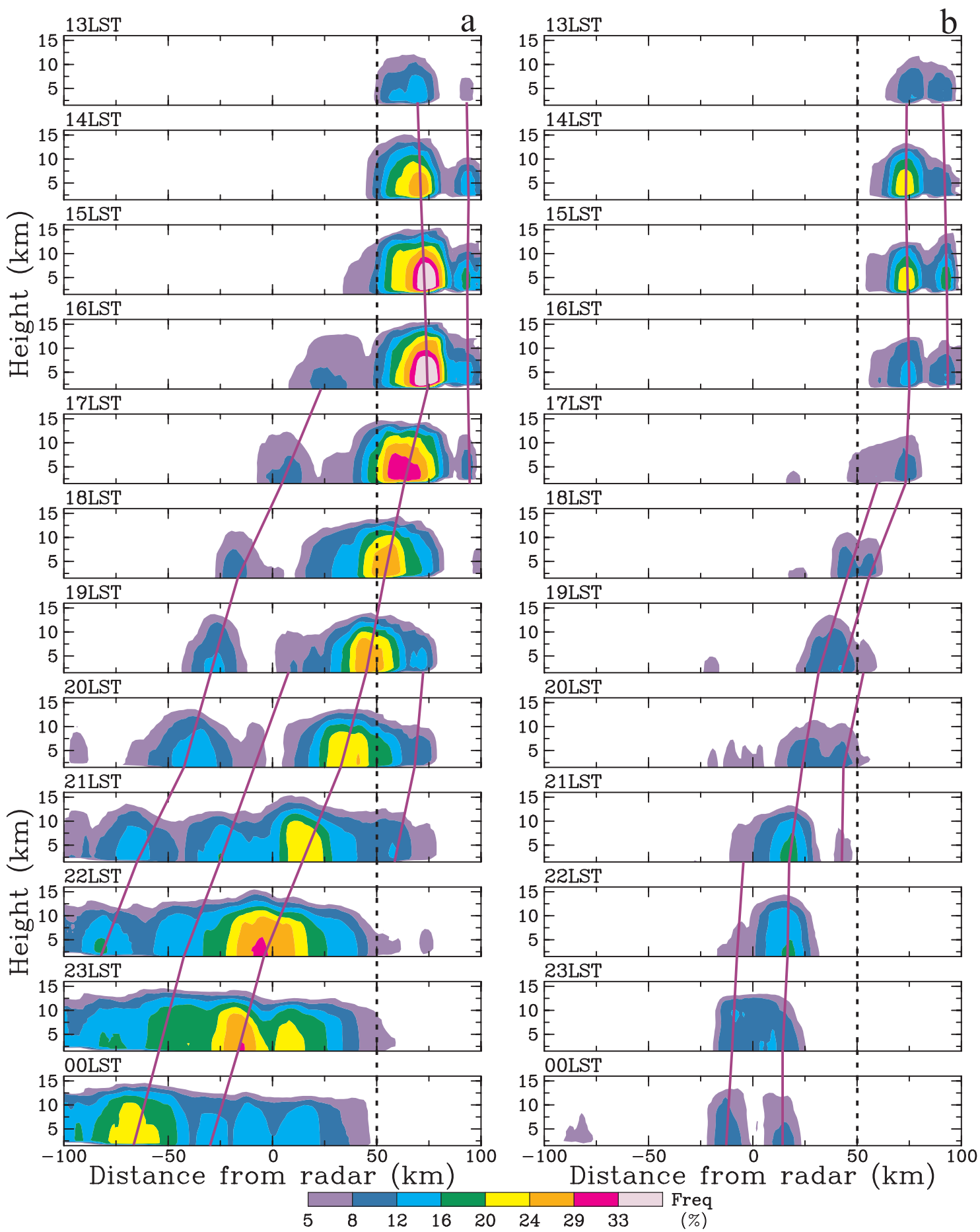

Fig. 7. (a) Shore-normal vertical sections of hourly occurrence frequency (color shades, \%) centered at the time labeled in each panel for convective echoes with reflectivity values of $\geq 10 \mathrm{dBZ}$ during the MRGW-offshore wind regime. The frequency is averaged in the shore-parallel direction between the two straight lines shown in Fig. 6 and traced by purple lines. The vertical dashed line indicates the approximate location of the shore. (b) Same as (a) but during the MRGW-onshore wind regime. 
MRGW-offshore wind regime

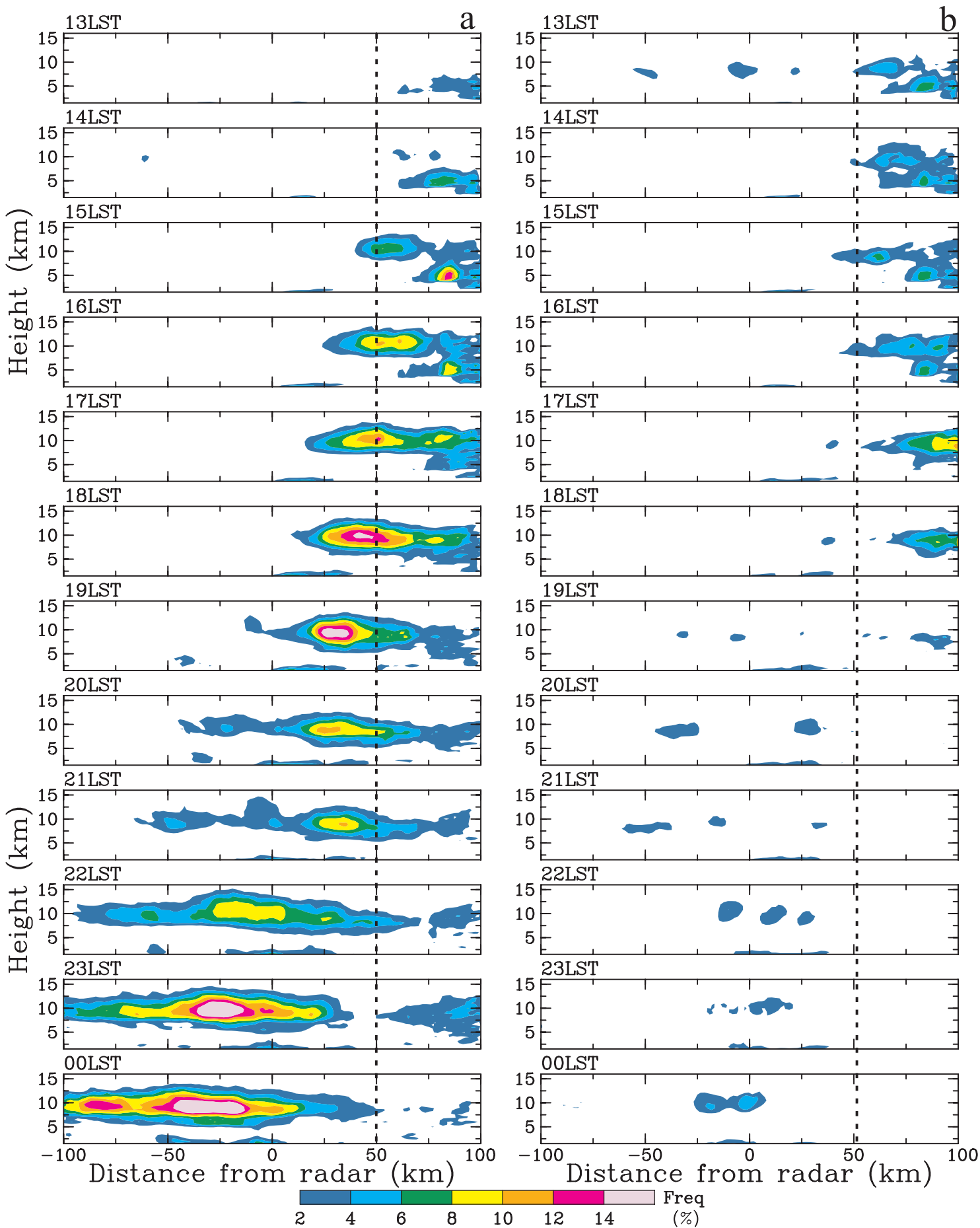

Fig. 8. (a) Shore-normal vertical sections of hourly occurrence frequency (color shades, \%) centered at the time labeled in each panel for stratiform echoes with specific differential phase $\left(K_{\mathrm{DP}}\right)$ values of $\geq 0.3^{\circ} \mathrm{km}^{-1}$ during the MRGW-offshore wind regime. The frequency is averaged in the shore-parallel direction between the two straight lines shown in Fig. 6. The vertical dashed line indicates the approximate location of the shore. (b) Same as (a) but during the MRGW-onshore wind regime. 


\section{Convective echoes}
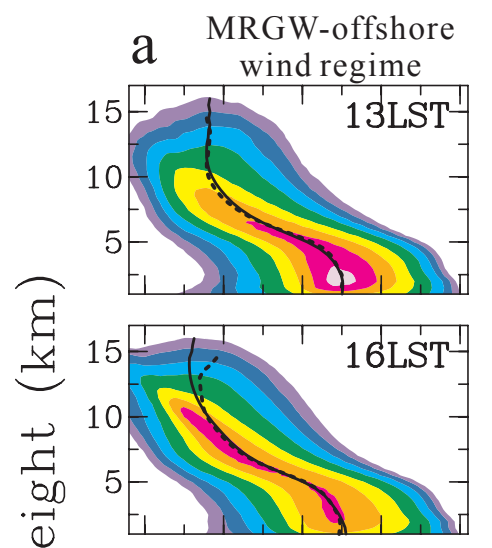

I
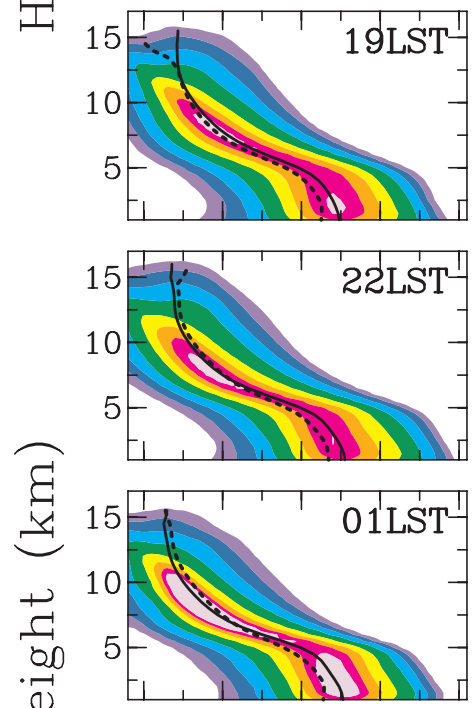

工1
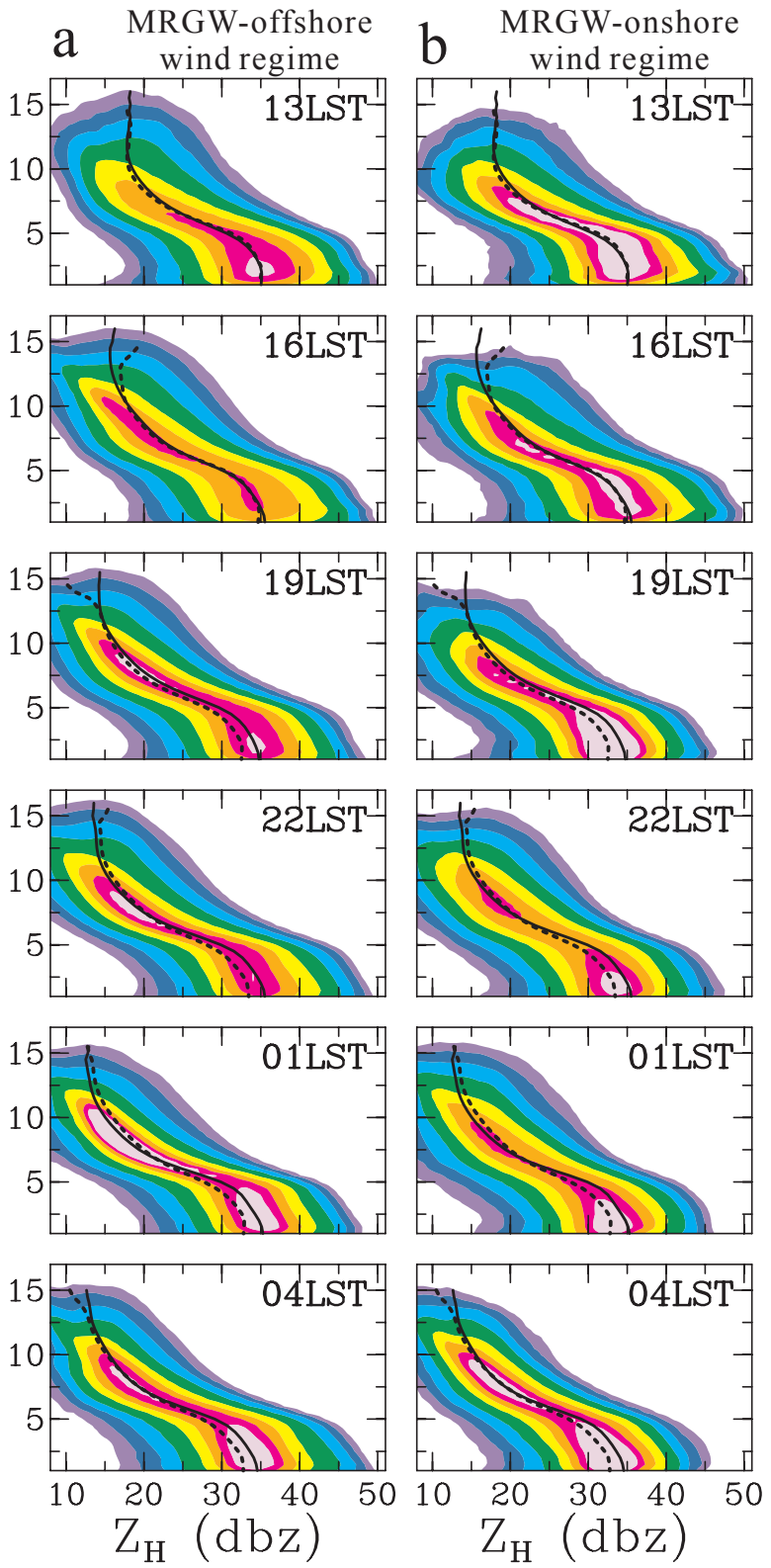

$0.01 \quad 0.02$

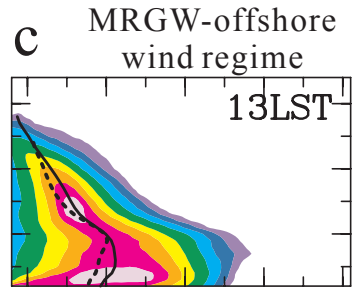

Stratiform echoes
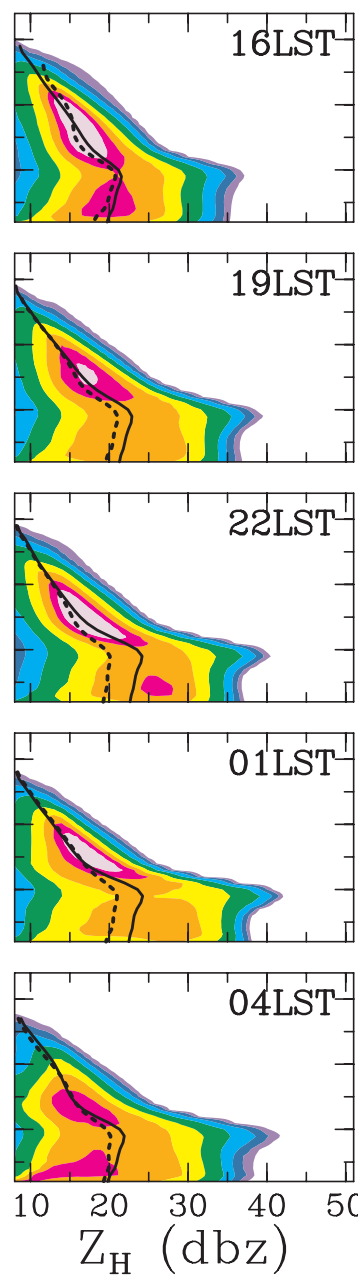
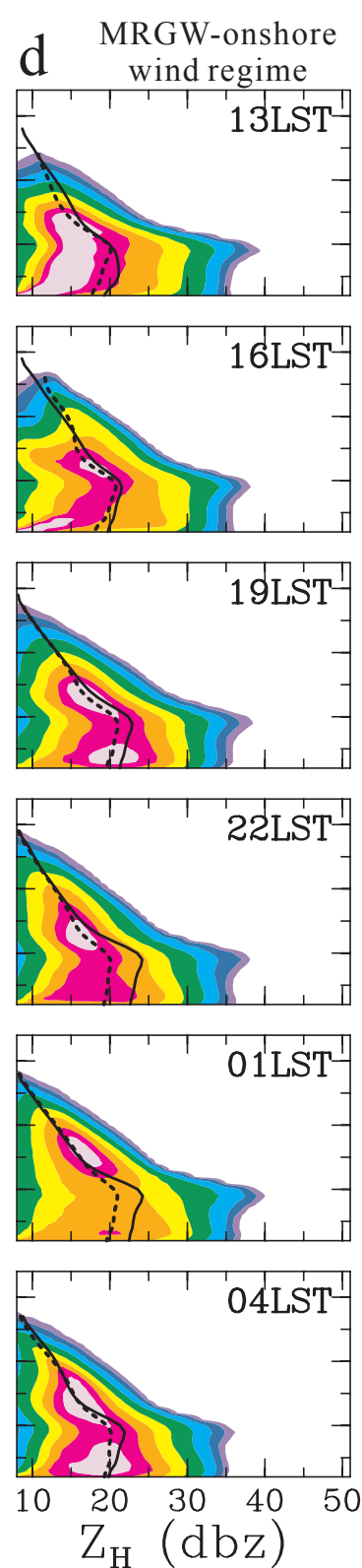
$\%$

Fig. 9. (a, b) Evolution of the three-hourly frequency-altitude distribution of convective echoes (color shades, \%) centered at the time labeled in each panel during (a) the MRGW-offshore wind regime and (b) the MRGW-onshore wind regime. $(c, d)$ Same as $(a, b)$ but for stratiform echoes. The solid and dashed curves in each panel represent the profiles of mean reflectivity for the MRGW-offshore and MRGW-onshore wind regimes, respectively. 
melting level $(\sim 5 \mathrm{~km})$ in stratiform FADs for both regimes, related to increased reflectivity aloft in convective FADs (Figs. 9a, b). The enhancement of stratiform reflectivity above the melting level occurred below the region with an increased presence of higher $K_{\text {DP }}$ values (Fig. 8) and was concentrated at heights of 6-8 km, where environmental temperatures ranged from $-5^{\circ} \mathrm{C}$ to $-17^{\circ} \mathrm{C}$. These results imply that the enhancement of stratiform reflectivity above the melting level can be attributed to processes such as aggregation (Houze 1993; Bechini et al. 2013). Similar to previous studies (e.g., Kennedy and Rutledge 2011; Kumjian and Lombardo 2017), the enhancement of $K_{\mathrm{DP}}$ and reflectivity values above the melting level was also linked to an increase in the intensity of stratiform echoes below the melting level. This linkage suggests that the development of ice hydrometeors in stratiform clouds leads to the intensification of stratiform precipitation.

Stratiform FADs showed that the occurrence of reflectivity values of $>30 \mathrm{dBZ}$ under the MRGW-offshore wind regime was larger as compared with that of the MRGW-onshore wind regime (Figs. 9c, d). The mean stratiform reflectivity values below $8 \mathrm{~km}$ during the MRGW-offshore wind regime were also larger than those during the MRGW-onshore wind regime. At 2200 LST, the mean near-surface stratiform reflectivity values during the MRGW-offshore wind regime were approximately $4 \mathrm{dBZ}$ larger as compared with those during the MRGW-onshore wind regime. These results suggest that diurnal stratiform precipitation during the MRGW-offshore wind regime was also stronger as compared with the MRGW-onshore wind regime.

\section{Mean diurnal cycle of rainfall and local environment under different regimes}

\subsection{Volume rainfall}

The time series of convective volume rainfall indicated that both regimes displayed two major diurnal peaks (Figs. 10a, b). The first peak occurred near 1500 LST and the second near 2200 LST, coinciding with convection development over the land and ocean, respectively (Fig. 6). There was a tendency for stratiform rainfall to peak following convective rainfall (Figs. 10a, b), in agreement with the result of enhanced stratiform precipitation following convection, as shown in Section 4 (Figs. 7, 8). These results indicate that the phase of the diurnal cycle is similar for both regimes. The peak timings of land- and ocean-based diurnal precipitation are consistent with previous studies (e.g., Mori et al. 2004; Kawashima et al. 2006; Sakurai et al. 2011; Yokoi et al. 2017).

The volume rainfall of convective and stratiform precipitation over both the land and the ocean during the MRGW-offshore wind regime was much larger as compared with the MRGW-onshore wind regime. The two convective rainfall peaks of the MRGW-offshore wind regime were at least twice as high as those of the MRGW-onshore wind regime, and a similar pattern was apparent for stratiform rainfall peaks. These results indicate that the amplitude of diurnal precipitation differs markedly between the two regimes, leading to the conclusion that the MRGW-offshore wind regime is favorable for the occurrence of more intense rainfall over both the land and the ocean.

\subsection{Local environment}

The development of a sea-breeze circulation was common in both regimes. Low-level onshore flow (i.e., sea-breeze flow) over the study site intensified after 1100 LST (Figs. 10c, d, g, h). Offshore flow above the sea-breeze flow, which peaked between $850 \mathrm{hPa}$ and $800 \mathrm{hPa}$, was associated with the sea-breeze return flow. In both regimes, the development of diurnal convection over land and its landward movement in the afternoon (Figs. 7, 10a, b) were coincident with the regular development of the sea-breeze flow.

However, the magnitudes of both the sea-breeze flow and the return flow during the MRGW-offshore wind regime were larger as compared with the MRGW-onshore wind regime. The maximum speed of the surface sea-breeze flow reached $4 \mathrm{~m} \mathrm{~s}^{-1}$ during the MRGW-offshore wind regime and approximately $2 \mathrm{~m} \mathrm{~s}^{-1}$ during the MRGW-onshore wind regime (Figs. $10 \mathrm{~g}, \mathrm{~h}$ ), indicating that the sea-breeze circulation is stronger under the MRGW-offshore wind regime. Figure 11 shows that, compared with the MRGW-onshore wind regime, the sea-breeze circulation during the MRGW-offshore wind regime was coincident with a larger shore-normal temperature gradient at low levels over the coastal ocean.

A land-breeze circulation also developed regularly in both regimes. The offshore propagation of diurnal convection from $\sim 1700$ LST (Fig. 7) was coincident with a decrease in the low-level onshore flow over the study site (Figs. 10c, d, g, h), suggesting the development of a land breeze in the early evening. The landbreeze circulation was observed over the study site after 2000 LST, as evidenced by the appearance of a relatively intense offshore flow near the surface and onshore flow aloft $(\sim 900 \mathrm{hPa})$. The reinforcement of convective rainfall over the ocean in both regimes (Figs. 10a, b) was coincident with the regular devel- 
MRGW-offshore wind regime

MRGW-onshore wind regime
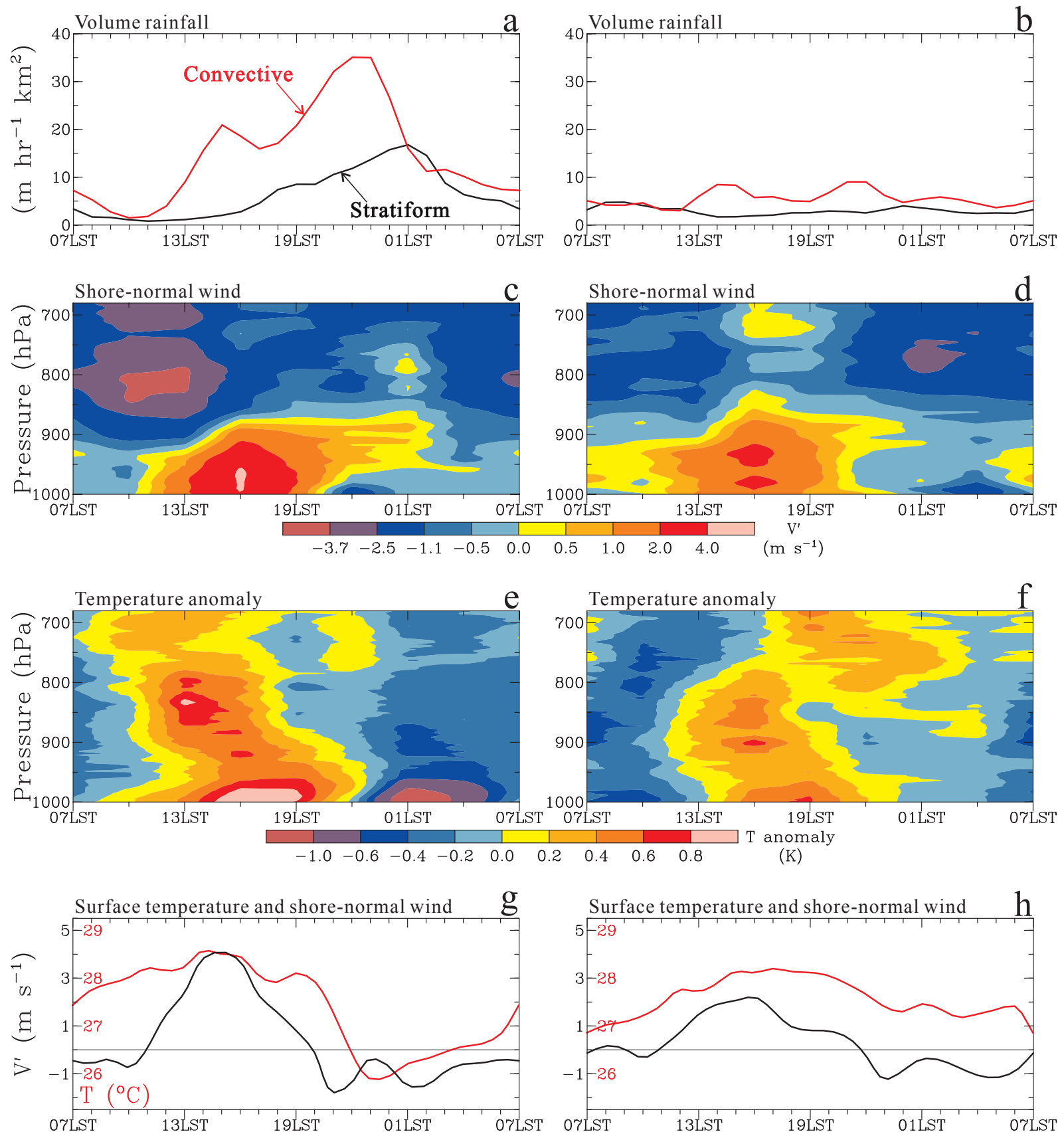

Fig. 10. (a, c, e, g) Mean diurnal cycles of rainfall and the local environment observed aboard the research vessel Mirai during the MRGW-offshore wind regime as illustrated by (a) the time series of volume rainfall from convective echoes (red curve, $\mathrm{m} \mathrm{h}^{-1} \mathrm{~km}^{2}$ ) and from stratiform echoes (black curve, $\mathrm{m} \mathrm{h}^{-1} \mathrm{~km}^{2}$ ), (c) the time-height section of the shore-normal wind component (color shades, $\mathrm{m} \mathrm{s}^{-1}$ ), (e) the time-height section of anomalous temperature (color shades, ${ }^{\circ} \mathrm{C}$ ), and (g) the time series of hourly mean surface temperature (red curve, ${ }^{\circ} \mathrm{C}$ ) and surface shore-normal wind speed (black curve, $\mathrm{m} \mathrm{s}^{-1}$ ). A temperature anomaly is defined as the deviation of temperature from its mean value at each height. Positive (negative) values of the shore-normal wind component represent onshore (offshore) winds. (b, d, f, h) Same as (a, c, e, g) but for mean diurnal cycles during the MRGW-onshore wind regime. 


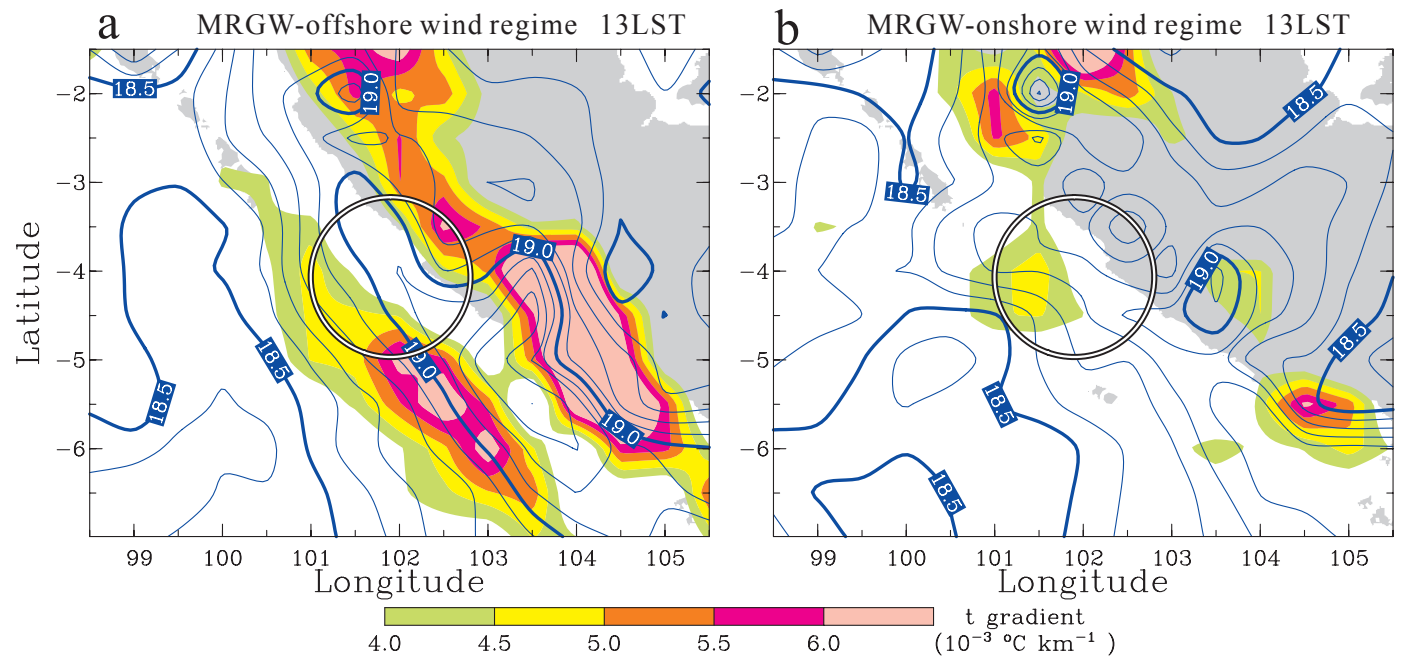

Fig. 11. (a) Mean $850 \mathrm{hPa}$ distribution of temperature (blue contours, ${ }^{\circ} \mathrm{C}$ ) and the shore-normal gradient of temperature (color shades, $10^{-3}{ }^{\circ} \mathrm{C} \mathrm{km}^{-1}$ ) derived from the global objective analysis (GPV) data at 1300 LST during the MRGW-offshore wind regime. The circle indicates the radar domain, and land areas are shaded in gray. (b) Same as (a) but during the MRGW-onshore wind regime.

opment of low-level offshore flow (i.e., land-breeze flow).

While the magnitude of the land-breeze flow in both regimes was comparable, the land-breeze flow in the MRGW-offshore wind regime was colder as compared with the MRGW-onshore wind regime (Figs. $10 \mathrm{c}-\mathrm{f}$ ). At 2200 LST, when convective rainfall peaked over the ocean (Figs. 10a, b), the mean surface temperature at the observation site was $25.9^{\circ} \mathrm{C}$ during the MRGW-offshore wind regime and $27.8^{\circ} \mathrm{C}$ during the MRGW-onshore wind regime (Figs. $10 \mathrm{~g}$, h). The colder land-breeze flow during the MRGW-offshore wind regime can be attributed to cooling induced by stronger and more widespread precipitation (Wu et al. 2009; Sakurai et al. 2011).

\section{Enhancement of diurnal precipitation by MRGWs}

It appears that the MRGW-offshore wind regime favors the development of intense diurnal convection and precipitation (Figs. 7, 10a, b). The presence of low-level convergence and upper-level divergence during the MRGW-offshore wind regime (Fig. 4e) is crucial for intense diurnal precipitation, because such a large-scale dynamic structure of the atmosphere is crucial for the growth of convection in the tropics (e.g., Cotton and Anthes 1989).

Sea- and land-breeze circulations are the two local circulations primarily responsible for triggering di- urnal cycles of precipitation over Sumatra. Through interactions with these local circulations, the intensification of the offshore wind component and low-level offshore wind shear during the MRGW-offshore wind regime can also favor the development of intense diurnal convection and precipitation; this is due to two main aspects.

First, the coincidence of the larger shore-normal gradient of temperature and the stronger sea-breeze flow during the MRGW-offshore wind regime (Figs. 10c, 11a) implies that the intensification of largescale offshore winds in this regime (Fig. 4a) facilitates the strengthening of the shore-normal gradient of temperature, thereby benefiting the development of the sea breeze through frontogenesis. Such a process is similar to the influence of large-scale winds on sea breeze illustrated by previous studies (e.g., Bechtold et al. 1991; Arritt 1993; Atkins and Wakimoto 1997). In turn, the enhanced sea breeze facilitates the development of strong diurnal convection and precipitation over land (Figs. 7a, 10a) and the formation of the colder land breeze (Fig. 10e).

In addition, as the circulation associated with offshore wind shear rotates in the opposite direction to the land-breeze circulation, the enhancement of lowlevel offshore wind shear during the MRGW-offshore wind regime (Figs. 2c, 4c) is effective in countering the colder land-breeze circulation, thereby promoting deeper lifting at low levels and the development of 
intense diurnal convection and precipitation over the ocean through the cold-pool-shear interaction process (Rotunno et al. 1988; Weisman and Rotunno 2004).

\section{Summary and conclusions}

In this study, modulation of the diurnal cycle of precipitation over the southwestern coastal area of Sumatra by westward-propagating mixed Rossby-gravity waves (MRGWs) was investigated. The variability of diurnal precipitation and local environment from 24 November to 12 December 2015, was analyzed using data from intensive surface observations, radiosondes, and a C-band polarimetric radar (collected aboard the research vessel Mirai at $\left.4^{\circ} 4^{\prime} \mathrm{S}, 101^{\circ} 54^{\prime} \mathrm{E}\right)$. Data were obtained during a pilot field campaign of the Years of the Maritime Continent (YMC) project. Largescale background conditions during this period were ascertained from global objective analysis data from the Japan Meteorological Agency.

Several westward-propagating MRGWs traversed the study site, inducing distinct offshore and onshore wind regimes. Around the study site, large-scale lowlevel convergence, upper-level divergence, and associated deep updrafts occurred in the MRGW-offshore wind regime, whereas large-scale low-level divergence, upper-level convergence, and associated deep downdrafts occurred in the MRGW-onshore wind regime. Low-level offshore wind shear was intensified during the MRGW-offshore wind regime. Local circulations also varied; the sea-breeze flow coincident with the larger shore-normal gradient of temperature was stronger and the land-breeze flow associated with deeper convection was colder in the MRGW-offshore wind regime as compared with the MRGW-onshore wind regime.

In contrast to their distinctive large-scale dynamic structures, the mean thermodynamic stratification of the free troposphere over the study site displayed no marked difference between the two regimes. The free atmosphere in both regimes was relatively moist and conditionally unstable, featuring moderate values of convective available potential energy (CAPE) and small values of convective inhibition (CIN).

The intensity of diurnal precipitation was characterized by multiday variations, and a relationship between these variations and the wind oscillations induced by MRGWs was apparent. Compared with the MRGW-onshore wind regime, diurnal convection was more active and widespread and convective precipitation more intense during the MRGW-offshore wind regime. Accompanied by deeper, stronger, and more widespread diurnal convection of the MRGW-offshore wind regime, stratiform clouds also exhibited more robust ice hydrometeors, leading to increased diurnal stratiform precipitation in this regime.

However, diurnal precipitation under both regimes displayed a similar well-defined phase and propagation pattern over both the land and the ocean, regardless of the wind regime induced by MRGWs. In both regimes, diurnal precipitation moved inland and peaked over land in the afternoon, moving seaward from the early evening and peaking again over the ocean at night. Both regimes saw the regular development of local sea- and land-breeze circulations from the late morning and early evening, respectively. Consequently, the diurnal cycle and propagation of precipitation in both regimes evolved in coherence with the regular evolution of sea- and land-breeze circulations.

Our analysis suggests that local convergence induced by the land-sea contrast is mainly responsible for driving the diurnal cycle. At the same time, MRGWs can exert a significant influence on the amplitude of diurnal convection and precipitation by modulating the large-scale dynamic structure of the atmosphere, the intensity of local sea- and land-breeze circulations, and the ability of these local circulations to trigger intense convection. Detailed processes related to the modulation of diurnal convection and precipitation by MRGWs need to be investigated thoroughly in the future.

\section{Acknowledgments}

The authors would like to express their sincere thanks to the crew of the research vessel Mirai and to the technical staff of Global Ocean Development Inc. for their support in conducting surface, radiosonde, and radar observations, and for data archiving. The authors also extend thanks to two anonymous reviewers for their constructive suggestions, which helped us to improve the clarity of the manuscript.

\section{References}

Arritt, R. W., 1993: Effects of the large-scale flow on characteristic features of the sea breeze. J. Appl. Meteor., 32, 116-125.

Atkins, N. T., and R. M. Wakimoto, 1997: Influence of the synoptic-scale flow on sea breezes observed during CaPE. Mon. Wea. Rev., 125, 2112-2130.

Baranowski, D. B., M. K. Flatau, P. J. Flatau, and A. J. Matthews, 2016: Phase locking between atmospheric convectively coupled equatorial Kelvin waves and the diurnal cycle of precipitation over the Maritime Continent. Geophys. Res. Lett., 43, 8269-8276.

Bechini, R., L. Baldini, and V. Chandrasekar, 2013: Polarimetric radar observations in the ice region of precipi- 
tating clouds at C-band and X-band radar frequencies. J. Appl. Meteor. Climatol., 52, 1147-1169.

Bechtold, P., J.-P. Pinty, and P. Mascart, 1991: A numerical investigation of the influence of large-scale winds on sea-breeze- and land-breeze-type circulations. J. Appl. Meteor, 30, 1268-1279.

Bringi, V. N., V. Chandrasekar, N. Balakrishnan, and D. S. Zrnić, 1990: An examination of propagation effects in rainfall on radar measurements at microwave frequencies. J. Atmos. Oceanic Technol., 7, 829-840.

Carey, L. D., S. A. Rutledge, D. A. Ahijevych, and T. D. Keenan, 2000: Correcting propagation effects in C-band polarimetric radar observations of tropical convection using differential propagation phase. $J$. Appl. Meteor., 39, 1405-1433.

Cotton, W. R., and R. A. Anthes, 1989: Storm and Cloud Dynamics. Academic Press, 883 pp.

Cressman, G. P., 1959: An operational objective analysis system. Mon. Wea. Rev., 87, 367-374.

Duchon, C. E., 1979: Lanczos filtering in one and two dimensions. J. Appl. Meteor, 18, 1016-1022.

Fujita, M., K. Yoneyama, S. Mori, T. Nasuno, and M. Satoh, 2011: Diurnal convection peaks over the eastern Indian Ocean off Sumatra during different MJO phases. J. Meteor. Soc. Japan, 89A, 317-330.

Hadi, T. W., T. Horinouchi, T. Tsuda, H. Hashiguchi, and S. Fukao, 2002: Sea-breeze circulation over Jakarta, Indonesia: A climatology based on boundary layer radar observations. Mon. Wea. Rev., 130, 2153-2166.

Hamada, J.-I., M. D. Yamanaka, S. Mori, Y. I. Tauhid, and T. Sribimawati, 2008: Differences of rainfall characteristics between coastal and interior areas of central western Sumatera, Indonesia. J. Meteor. Soc. Japan, 86, 593-611.

Houze, R. A., Jr, 1989: Observed structure of mesoscale convective systems and implications for large-scale heating. Quart. J. Roy. Meteor. Soc., 115, 425-461.

Houze, R. A. Jr., 1993: Cloud Dynamics. Academic Press, 573 pp.

Ichikawa, H., and T. Yasunari, 2007: Propagating diurnal disturbances embedded in the Madden-Julian Oscillation. Geophys. Res. Lett., 34, L18811, doi:10.1029/ 2007 GL030480.

Jackson, B., S. E. Nicholson, and D. Klotter, 2009: Mesoscale convective systems over western equatorial Africa and their relationship to large-scale circulation. Mon. Wea. Rev., 137, 1272-1294.

Kamimera, H., S. Mori, M. D. Yamanaka, and F. Syamsudin, 2012: Modulation of diurnal rainfall cycle by the Madden-Julian oscillation based on one-year continuous observations with a meteorological radar in west Sumatera. SOLA, 8, 111-114.

Katsumata, M., 2014: On the new shipboard Doppler radar of the R/V Mirai. Tenki, 61, 871-875 (in Japanese).

Kawashima, M., Y. Fujiyoshi, M. Ohi, T. Honda, T. Kozu, T. Shimomai, and H. Hashiguchi, 2006: Overview of Doppler radar observations of precipitating cloud systems in Sumatera Island during the first CPEA campaign. J. Meteor. Soc. Japan, 84A, 33-56.

Kawashima, M., Y. Fujiyoshi, M. Ohi, T. Honda, S. Mori, N. Sakurai, Y. Abe, W. Harjupa, F. Syamsudin, and M. D. Yamanaka, 2011: Case study of an intense wind event associated with a mesoscale convective system in west Sumatera during the HARIMAU2006 campaign. J. Meteor. Soc. Japan, 89A, 239-257.

Keenan, T., S. Rutledge, R. Carbone, J. Wilson, T. Takahashi, P. May, N. Tapper, M. Platt, J. Hacker, S. Sekelsky, M. Moncrieff, K. Saito, G. Holland, A. Crook, and K. Gage, 2000: The Maritime Continent Thunderstorm Experiment (MCTEX): Overview and some results. Bull. Amer. Meteor. Soc., 81, 2433-2455.

Kennedy, P. C., and S. A. Rutledge, 2011: S-band dualpolarization radar observations of winter storms. $J$. Appl. Meteor. Climatol., 50, 844-858.

Kiladis, G. N., M. C. Wheeler, P. T. Haertel, K. H. Straub, and P. E. Roundy, 2009: Convectively coupled equatorial waves. Rev. Geophys., 47, RG2003, doi:10.1029/ 2008RG000266.

Kumjian, M. R., and K. A. Lombardo, 2017: Insights into the evolving microphysical and kinematic structure of northeastern U.S. winter storms from dual-polarization Doppler radar. Mon. Wea. Rev., 145, 1033-1061.

Lang, T. J., D. A. Ahijevych, S. W. Nesbitt, R. E. Carbone, S. A. Rutledge, and R. Cifelli, 2007: Radar-observed characteristics of precipitating systems during NAME 2004. J. Climate, 20, 1713-1733.

Madden, R. A., and P. R. Julian, 1972: Description of globalscale circulation cells in the tropics with a 40-50 day period. J. Atmos. Sci., 29, 1109-1123.

Mandapaka, P. V., U. Germann, and L. Panziera, 2013: Diurnal cycle of precipitation over complex Alpine orography: Inferences from high-resolution radar observations. Quart. J. Roy. Meteor. Soc., 139, 10251046.

Mori, S., J.-I. Hamada, Y. I. Tauhid, M. D. Yamanaka, N. Okamoto, F. Murata, N. Sakurai, H. Hashiguchi, and T. Sribimawati, 2004: Diurnal land-sea rainfall peak migration over Sumatera Island, Indonesian Maritime Continent, observed by TRMM satellite and intensive rawinsonde soundings. Mon. Wea. Rev., 132, 2021-2039.

Mori, S., J.-I. Hamada, N. Sakurai, H. Fudeyasu, M. Kawashima, H. Hashiguchi, F. Syamsudin, A. A. Arbain, R. Sulistyowati, J. Mastumoto, and M. D. Yamanaka, 2011: Convective systems developed along the coastline of Sumatera Island, Indonesia, observed with an X-band Doppler radar during the HARIMAU2006 campaign. J. Meteor. Soc. Japan, 89A, 61-81.

Nakagawa, M., 2009: Outline of the high resolution global model at the Japan Meteorological Agency. RSMC Tokyo-Typhoon Center Technical Review, 11, 1-13. [Available at http://www.jma.go.jp/jma/jma-eng/jma- 
center/rsmc-hp-pub-eg/techrev/text11-1.pdf.]

Numaguti, A., R. Oki, K. Nakamura, K. Tsuboki, N. Misawa, T. Asai, and Y.-M. Kodama, 1995: 4-5-day-period variation and low-level dry air observed in the equatorial western Pacific during the TOGA-COARE IOP. J. Meteor. Soc. Japan, 73B, 267-290.

Peatman, S. C., A. J. Matthews, and D. P. Stevens, 2014: Propagation of the Madden-Julian Oscillation through the Maritime Continent and scale interaction with the diurnal cycle of precipitation. Quart. J. Roy. Meteor. Soc., 140, 814-825.

Ramage, C. S., 1968: Role of a tropical "Maritime Continent" in the atmospheric circulation. Mon. Wea. Rev., 96, 365-370.

Rauniyar, S. P., and K. J. E. Walsh, 2011: Scale interaction of the diurnal cycle of rainfall over the Maritime Continent and Australia: Influence of the MJO. J. Climate, 24, 325-348.

Renggono, F., H. Hashiguchi, S. Fukao, M. D. Yamanaka, S.-Y. Ogino, N. Okamoto, F. Murata, B. P. Sitorus, M. Kudsy, M. Kartasasmita, and G. Ibrahim, 2001: Precipitating clouds observed by $1.3-\mathrm{GHz}$ boundary layer radars in equatorial Indonesia. Ann. Geophys., 19, 889-897.

Rotunno, R., J. B. Klemp, and M. L. Weisman, 1988: A theory for strong, long-lived squall lines. J. Atmos. Sci., 45, 463-485.

Roundy P. E., and C. J. Schreck III, 2009: A combined wave-number-frequency and time-extended EOF approach for tracking the progress of modes of largescale organized tropical convection. Quart. J. Roy. Meteor. Soc., 135, 161-173.

Sakurai, N., S. Mori, M. Kawashima, Y. Fujiyoshi, J.-I. Hamada, S. Shimizu, H. Fudeyasu, Y. Tabata, W. Harjupa, H. Hashiguchi, M. D. Yamanaka, J. Matsumoto, Emrizal, and F. Syamsudin, 2011: Migration process and 3D wind field of precipitation systems associated with a diurnal cycle in west Sumatera: Dual Doppler radar analysis during the HARIMAU2006 campaign. J. Meteor. Soc. Japan, 89, 341-361.

Takasuka, D., M. Satoh, and S. Yokoi, 2019: Observational evidence of mixed Rossby-gravity waves as a driving force for the MJO convective initiation and propagation. Geophys. Res. Lett., 46, 5546-5555.

Takayabu, Y. N., and T. Nitta, 1993: 3-5 day-period disturbances coupled with convection over the tropical Pacific Ocean. J. Meteor. Soc. Japan, 71, 221-246.
Vincent, C. L., and T. P. Lane, 2017: A 10-year austral summer climatology of observed and modeled intraseasonal, mesoscale, and diurnal variations over the Maritime Continent. J. Climate, 30, 3807-3828.

Weisman, M. L., and R. Rotunno, 2004: "A theory for strong long-lived squall lines” revisited. J. Atmos. Sci., 61, 361-382.

Wheeler, M., and G. N. Kiladis, 1999: Convectively coupled equatorial waves: Analysis of clouds and temperature in the wavenumber-frequency domain. J. Atmos. Sci., 56, 374-399.

Widiyatmi, I., H. Hashiguchi, S. Fukao, M. D. Yamanaka, S.-Y. Ogino, K. S. Gage, S. W. B. Harijono, S. Diharto, and H. Djojodihardjo, 2001: Examination of 3-6 day disturbances over equatorial Indonesia based on boundary layer radar observations during 1996-1999 at Bukittinggi, Serpong and Biak. J. Meteor. Soc. Japan, 79B, 317-331.

Wu, P., M. Hara, J.-I. Hamada, M. D. Yamanaka, and F. Kimura, 2009: Why a large amount of rain falls over the sea in the vicinity of western Sumatra Island during nighttime. J. Appl. Meteor. Climatol., 48, 1345-1361.

Yamanaka, M. D., 2016: Physical climatology of Indonesian maritime continent: An outline to comprehend observational studies. Atmos. Res., 178-179, 231-259.

Yang, G.-Y., and J. Slingo, 2001: The diurnal cycle in the Tropics. Mon. Wea. Rev., 129, 784-801.

Yasunaga, K., K. Yoneyama, Q. Moteki, M. Fujita, Y. N. Takayabu, J. Suzuki, T. Ushiyama, and B. Mapes, 2010: Characteristics of 3-4- and 6-8-day period disturbances observed over the tropical Indian Ocean. Mon. Wea. Rev., 138, 4158-4174.

Yokoi, S., S. Mori, M. Katsumata, B. Geng, K. Yasunaga, F. Syamsudin, Nurhayati, and K. Yoneyama, 2017: Diurnal cycle of precipitation observed in the western coastal area of Sumatra Island: Offshore preconditioning by gravity waves. Mon. Wea. Rev., 145, 37453761.

Yuter, S. E., and R. A. Houze, Jr., 1995: Three-dimensional kinematic and microphysical evolution of Florida cumulonimbus. Part II: Frequency distributions of vertical velocity, reflectivity, and differential reflectivity. Mon. Wea. Rev., 123, 1941-1963.

Yuter, S. E., and R. A. House, Jr., 1998: The natural variability of precipitating clouds over the western Pacific warm pool. Quart. J. Roy. Meteor. Soc., 124, 53-99. 